\title{
Examination of Sports Entrepreneurship and Entrepreneurial Strategy
}

\author{
Joshua Senne, MS, SCPM \\ jasenne@ussa.students.edu
}

\begin{abstract}
This paper presents an overview of five topics related to sports entrepreneurship and entrepreneurial strategy. These topics include (a) entrepreneurship and sport, (b) entrepreneurial characteristics, (c) entrepreneurial strategies, $(d)$ a case of entrepreneurial success in sports, (e) and a case of entrepreneurial failure in sports. For each topic, this paper presents an overview as well as a reason for selecting the topic. Further, this paper presents information about the importance of each topic related to entrepreneurship in sports, plus any relevant social, ethical, or legal concerns.
\end{abstract}

Keywords: entrepreneurship, entrepreneurial strategy, sports entrepreneurship, entrepreneurial success, entrepreneurial failure, sport entrepreneur, entrepreneur.

\section{INTRODUCTION}

In today's society, one is beginning to see an increase in the number of start-ups, small businesses, and franchises that are popping up in the free economy of the United States. One will find at the head of these ventures is an entrepreneur or group of entrepreneurs heading the development and launch, day to day activities, and other necessary actions to make the business venture a success. Also, some entrepreneurs develop new products to put on the market, or reinvent current products for better utility. According to www.merriam-webster.com, the simple definition of entrepreneur is "a person who starts a business and is willing to risk loss in order to make money." The full definition is "one who organizes, manages, and assumes the risks of a business or enterprise."

Looking at the definition of entrepreneur and seeing that it requires one to be organized, manage the venture, and also, assume risks of the business, it can be stated that entrepreneurship requires one to be capable of developing and initiating successful entrepreneurial strategy (21). What exactly is entrepreneurship? Entrepreneurship is a way for countries to grow and become successful (1). It is how economies become successful and grow, and in order for this to be possible, people must transform their ideas and recognized opportunities into successful business ventures. Further, entrepreneurship is a way of thinking, reasoning, or taking action that is driven by opportunity, holistic in nature, and leadership oriented (22).

Sport entrepreneurship is any activity in the realm of sport that is innovative, opportunity driven, and also competitively aggressive $(15,16)$. With that being stated, one can see that entrepreneurship is relative to sport business and requires one to be able to exploit opportunities, take risks, be an innovative thinker, and also be leadership-oriented. However, what kind of strategy would a sport entrepreneur use to initiate a venture in sport, and also maintain the success of that venture for strategic growth? There is little research on the topic of sport entrepreneurship, especially on entrepreneurial strategy in sport business. It is important for entrepreneurs of sport to have a strategic plan for success in the realm of sport business.

\section{REVIEW OF THE LITERATURE}

\subsection{Entrepreneurship and Sport}

One can look at sports entrepreneurship from many different perspectives, but two ways in which sports and entrepreneurship are strongly related are the ways in which businesses utilize sports because it has universal global appeal due to entrepreneurship in the competitive marketplace and sport franchises, which are directly related to the sports industry (16). A couple of examples would be 
the way in which Red Bull utilized the sport industry to launch itself into the sport industry, first by sponsorship of sports and then by creating sports teams and events directly. Red Bull is a huge success because it utilized these two different frameworks for entrepreneurial success, along with quite a few different entrepreneurial strategies, which will be discussed later.

As previously stated, sport entrepreneurship is considered to include any type of sport activity that is innovative, opportunity-driven, and competitively aggressive (15). Much like entrepreneurship is important to business in the way that it helps in the development of the enterprise with economic advancement, the main goal of a sports entrepreneur is to be highly impactful in his or her field of sport, and also in other areas such as social and environmental ways that impact sports development (17). Further, sports entrepreneurs are people or organizations in sport that use innovation to solve business related issues in sport, and when solved, have the ability to change the business environment for the better (11).

Different types of entrepreneurs in sport can include the athletes, agents, towns, and the owners, as long as they are doing something in sport that is different from what has been done before. This involves international dimensions that can affect the development of sport, and also help in the innovation of new inventions that can further affect sport (16). Further, sports entrepreneurship is important to international management because it can enable businesses to adapt to societal trends (16).

\subsection{Entrepreneurial Characteristics}

As previously stated, entrepreneurs have certain characteristics that can be attributed to their success, and in many cases, must have in order to become successful because being an entrepreneur, and especially in the realm of sport, takes a certain kind of demeanor to successfully implement and manage a sport venture. A study found that founder's identity plays an important role in the type of venture an entrepreneur chooses and how it is run (5). In discussing entrepreneurial characteristics, there are those that are psychological, like personality characteristics, and then there are those that are demographic, like age, race, gender, and educational level. That being stated, one will discuss the different entrepreneurial characteristics related to both psychology and demographics.

According to a study, entrepreneurial orientation can be described by five different variables, which are autonomy, innovativeness, risk-taking, proactiveness, and competitiveness (14). Furthermore, there is research to support that gender affects the entrepreneurial orientation of individuals, and also, that males have a higher orientation $(21,25)$. A study tested for entrepreneurial characteristics in final year college students in the School of Physical education and Sports at Sakarya, Kocaeli and Mugla Universities, which consisted of 242 students who voluntarily participated in the research (9).

The results of the descriptive factor analysis found that the students defined their entrepreneurial characteristics in five sub-dimensions, which are innovativeness, tolerance for ambiguity, risk-taking, need for achievement, and locus of control (9). Based on the break down of the different departments, the dimension with the highest value was "innovativeness" for the department of sports management, "need for achievement" for the departments of physical education and sports teaching, coaching education and recreation, and the dimension with the lowest value is "locust of control" for all departments. This study also found that having an entrepreneur in the family had an effect on the dimensions of innovativeness, tolerance for ambiguity, and risk taking, which are characteristics necessary for entrepreneurship (9). From the results of this study, it can be seen that students of sport management have a higher inclination for innovativeness, which is a key player in the success of an entrepreneur.

According to a study, entrepreneurs display behaviors of obsessed maniacs and clairvoyant oracles (2). What this means is that issues that arise in the realm of obsession for the entrepreneur are workaholism, perfectionism, control issues, difficulty accepting rejection of ideas, stubborn, and never giving up. Further, issues arising from mania include aggressiveness, winging it without a plan, restlessness and always moving ahead, and exaggerated optimism, passion, or excitement (2). Under the term clairvoyant and oracle in the study, characteristics such as natural salesperson, persuasiveness, vision, actively positioning for an opportunity, and making good luck scenarios occur, were associated.

Most entrepreneurs initiate their entrepreneurial careers between the ages of 22 and 45 (22). However, they state, "a career can be initiated before or after these ages, as long as the entrepreneur has the 
necessary experience and financial support, and the high energy level needed to manage a new venture successfully (22)." Furthermore, it is said that there are milestone ages every five years (25, 30, 35, 40, and 45) (22). According to a research study from the Kauffman Foundation for entrepreneurial data in America, gender of entrepreneurs shifted from 56\% for males and $44 \%$ females in 1996, to 62\% male and 38\% female in 2011 (15). Further, in 1996, 35\% of entrepreneurs were ages $20-34,27 \%$ ages $35-44,24 \%$ ages $45-54$, and $14 \%$ ages $55-64$, whereas in $2011,29 \%$ were ages $20-34,28 \%$ ages $35-44,22 \%$ ages $45-54$, and $21 \%$ ages 55-64 (15).

Data for race of entrepreneurs showed that in 1996, $77 \%$ where white, $11 \%$ were Latino, $9 \%$ were black, and $4 \%$ were Asian, whereas in 2011, 60\% were white, 23\% Latino, 9\% were black, and 5\% were Asian. The data shows that over time, the age of entrepreneurs is increasing and the number of white entrepreneurs in America is decreasing with an increase in the races other than white. According to a study, "more than 90 percent of entrepreneurs came from middle-class or upper-lowerclass backgrounds and were well educated. Further, founders tended to be middle aged (40 years) when they started their first company (24)." "70 percent were married when they became entrepreneurs, and 60 percent had at least one child (24)."

Many people feel that entrepreneurs are less educated than the general population, and research findings clearly find that this is not the case (11). Education is very important in the upbringing of the entrepreneur (11). The importance is not only found in the level of education obtained, but also that the education they obtain continuously helps them cope with the many problems they may face in their ventures (11). Further, it has been shown that it is even more helpful when the type of education obtained is pertinent to the type of venture an entrepreneur is partaking in because entrepreneurs have cited a need for understanding in the areas of finance, strategic planning, marketing, and management (11).

According to a study, 95.1 percent of study participants had earned bachelor's degrees, and 47 percent had earned more advanced degrees (24). Further, seventy-five percent of the respondents ranked their academic performance among the top 30 percent of their high school classes, and 52 percent said they ranked among the top 10 percent (24). Also, for respondent college degrees, it was found that 67 percent of the founders ranked among the top 30 percent of their undergraduate classes, and 37 percent ranked their performance among the top ten percent. Even a "general education is valuable because it facilitates the integration and accumulation of new knowledge, providing individuals with a larger opportunity set, and assists entrepreneurs in adapting to new situations (12)."

\subsection{Entrepreneurial Strategies Covered in the Literature}

To be a successful sports entrepreneur, one needs to have a sound strategic plan that is successful and relevant to the sport venture. What this means is that different types of entrepreneurial ventures will require different types of entrepreneurial strategies. One would not want to have the same strategic plan for a small sports club and a large pro sports league franchise. One will present the different types of strategies covered in previous research and discuss the applications of each in the realm of sport entrepreneurship.

A study investigated the strategic planning initiatives of small sports clubs (SSCs) in Germany and Ireland (6). The purpose of the study was to examine how SSCs manage and execute fundraising activities, and then how these SSCs can maximize their fundraising activities. The study looked at 19 different clubs in Germany and Ireland. The key informants belonged to clubs that fit the criteria of a SSC. Further, the researchers used semi-structured interviews, while using an interview guide with key topics and questions. The study adopted a qualitative methodology, and in-depth interviews were chosen for data collection because they were considered better for gathering deep insight on sensitive information.

The research showed that there was little recognition of a formal strategic plan used by the clubs, with only 5 clubs stating they had used some form of plan. 16 of the SSCs said they had considered the current internal situation of the clubs when looking at fundraising and found that only one club looked at the external environment to identify and analyze opportunities and threats. 11 clubs stated the importance of personal contacts in acquiring resources and funding, and only 5 clubs stated they had used some form of a formal tactical plan. All clubs considered the importance of volunteers to the success and survival of their clubs. The study found that overall, SSCs range from being proactive to relatively inactive, and that the role of SSC manager is of crucial importance. 
Based on the overall results of the study, one concluded that a social entrepreneur would be highly beneficial for an SSC because social entrepreneurs with experience of business activities are able to lead SSCs to success with their expertise and help build relationships with key people and increase professionalism of the SSC (6). Further, social entrepreneurs can develop a communication and promotion strategy that will help create awareness and spread information about the activities of the SSC. Also, they can develop communication that relays the benefits of the SSC to the stakeholders such as individuals and the community so that expectations can be set and monitored (6). This research shows the importance of having a strategic plan when running a sport venture, but especially a smaller sport venture that depends on the sociability of the manager for monetary success.

Opportunities for new entry are generated by the knowledge of the entrepreneur and from organizational knowledge (12). That being said, this is the basis for one when deciding on the best place to look for opportunities to grow the business (12). A chart was developed in which different combinations of these types of knowledge are represented, and based on the level of new or existing markets and products, one can use a certain strategy for growth (12). These 4 growth strategies include penetration strategies, product development strategies, market development strategies, and diversification strategies.

Penetration strategies focus on a firm's existing products and existing market, and the entrepreneur attempts to penetrate this product or market further by encouraging existing customers to buy more of the firm's current products (12). Market development strategies are when a firm's existing products are sold to new groups of customers, and these new groups of customers can be categorized based on new geographic markets, new demographic markets, and new product use (12). Next, there are product development strategies, which involves a firm developing and selling new products to people who are consumers of the firms existing products (12). Lastly, there are diversification strategies, which involve selling a new product to a new market (12).

Entrepreneurs can exploit opportunities to achieve success (19). These different ways of exploiting opportunities include new methods of production, new sources of supply, new products or services, new markets, new forms of organization, and any combination of the aforementioned ways. Further, in relation the these methods, there is a sixth way in which entrepreneurs can exploit opportunities, and that is through the use of innovative marketing strategies, philosophies, and techniques (10). However, a study found that autonomy and innovation in marketing techniques did not seem to have a significant impact on marketing excellence when studying the organizational practices of 16 American professional sport franchises (13).

\subsection{A Case of Entrepreneurial Success in Sports}

Now that one has discussed the meaning of entrepreneurship and the characteristics and strategies, one will examine a case of where a company that sells energy drinks was able to penetrate the sport market and redefine it with different entrepreneurial strategies. One will examine the character of the founder and the different strategies he used to turn his company in to a global success. Also, one will examine how this company became a popular name brand in the sports industry. The organization that will be discussed is Red Bull, and the founder is Dietrich Mateschitz, who in 2004 owned 70 percent of the energy drinks market and was worth 2.5 billion (7). Today, the number is much greater.

Red Bull is successful because it was able to utilize intelligent marketing and patient and strategic growth by way of local distribution to international distribution (10). It did a great job of differentiating its brand from other canned beverages like Coca-Cola and Pepsi by using unique colors on the can, a distinctive can shape, and charging a higher price so that people would know they were buying a premium product that was deserving of a higher price and worth the higher price. Mateschitz was able to recognize the exploitative opportunities in the sport industry for his brand, and he understood the value of the sport market. Based on this understanding, he built a brand based on extreme sports and fast living and capitalized on the global marketplace (10)

Based on the aforementioned exploitive opportunities, a case study was developed around the Red Bull brand, and identified how it became the entrepreneurial success in the sport industry that it is today $(10,18)$. Red Bull utilized new methods of production by employing decentralized sales and marketing teams and building the Red Bull brand from the bottom up. Further, they employed social entrepreneurship as previously discussed by building relationships with key stakeholders like cultural 
icons, focusing on local and influential DJs, clubbers, ravers, social trendsetters, and through word of mouth $(6,10)$.

Red Bull recognized new sources of supply and integrated itself into the extreme sports industry by creating a new sport called Flugtag in 1991 (10). The sport first launched in Vienna, Austria, and required people to design and build flying contraptions that were to be launched off of a $9.1 \mathrm{~m}$ high ramp (10). Creating this extreme sport exemplified the brand as a product that "Gives You Wings", which is the brand motto. Mateschitz opened a door for Red Bull to enter the sports market by creating this extreme sport and by creating an extreme sport that correlated with brand image and motto. Another sport they created in 2000, called Red Bull Crashed Ice, was a combination of hockey, downhill skiing, and boardercross, representing a new breed of sporting events, which were created by the Red Bull brand (10). Red Bull was the first brand to create an actual sport to promote its brand in extreme sports, and it shows how it recognized the entrepreneurial opportunity of offering new products and services $(12,19)$. Red Bull was able to gain the support and attention of generation $\mathrm{X}$ and $\mathrm{Y}$ by exploiting the sport industry in that it created new sports of its own, and it used social entrepreneurship to build repertoire with its target market.

\subsection{A Case of Entrepreneurial Failure in Sports}

Often times, entrepreneurial ventures fail due to many different circumstances, and while one can begin a new venture with a sound strategy, it is possible to still fail due to unforeseen circumstances or a misunderstanding of the target market. A study was conducted to understand why 3 different professional women's volleyball leagues failed to maintain themselves in the United States sport market (3). The three leagues that will be examined are Major League Volleyball (MLV, 1987-1989), National Volleyball Association (NVA, 1993-1998), and the United States Professional Volleyball League (USPV, 2002-2003).

Upon analyzing the three leagues, it was found that the leagues failed due to the entrepreneurial framework for which they used to approach the management of the venture (3). The researchers stated that the leagues failed to understand the institutionalized approach to maintaining the ventures, which doesn't consider too well the duration, pacing, and required level of effort necessary to be successful (3). Further, institutionalists assume that the clock moves slowly and consider historical evidence in empirical models, but do not recognize the importance of sense or passing of time (3).

Essentially, what this means for the Volleyball leagues is that they sought to develop a successful product, gain legitimacy, and recognition for their organizations, while becoming a profitable organization for their entrepreneurial ventures in a short amount of time. What they failed to realize is that organizations and the entire industry required legitimization, and as the institutional approach suggests, to "alter patterned behaviors that are infused with meanings and perpetuated by social exchanges requires a much longer time; the duration of these changes is typically years, if not decades (3)." That being stated, one can see that the entrepreneurial and institutional approach to starting a sport league/venture are asynchronous, which led to the repeated failures of the women's volleyball leagues.

The entrepreneurs did not recognize or possibly misinterpreted the institutional environment, and utilized a set of resources that proved to be inadequate to gain the necessary recognition needed to legitimize the women's volleyball leagues (3). Further, they struggled to gain recognition from the media and corporate sponsors as a professional sport, and often, they were mistakenly recognized as a collegiate sport. A study found that women in the sport industry, and especially women sport leagues are often underrepresented due to "gender marking", which is when women sports are seen as "other" and not as important as male sports leagues (20).

This caused them to fail to be seen as a legitimate sport entertainment product, which made it difficult to gain demand for the product and also product sponsors. Therefore, they were unable to sustain operations for the long term. This case is important because it shows the importance of recognizing the landscape for which entrepreneurs in sport may try to enter, and the strategies they will need to use in order to sustain successful operations. If the women's volleyball teams had been aware and understood the importance of being able to develop legitimacy of the sport and had seen the difficulty in carrying out such a task, it is probable they would have recognized the potential failure and planned more effectively, or not pursued the venture. 


\section{SUMMARY}

An entrepreneur is someone who organizes, manages, and assumes the risk of a business, a person willing to risk loss in order to make money, and also, a person who is innovative, driven, and competitively aggressive $(1,22)$. Furthermore, it is someone who is able to exploit opportunities, take risks, be an innovative thinker, and someone who is leadership oriented. A common theme given in the definition of an entrepreneur is that it is someone that exploits opportunities by recognizing them and essentially doing something that has never been done before, an innovative leader. Entrepreneurship was similarly defined as a way of thinking, reasoning, or taken action that is driven by opportunity, holistic in nature, and leadership oriented (23).

Sport entrepreneurship is defined as being an activity in sport where innovation, opportunity, and competitive aggression are present $(15,16)$. Sports and entrepreneurship are strongly related in the ways in which businesses utilize sports because it has universal global appeal due to entrepreneurship in the competitive marketplace, and then sport franchises, which are directly related to the sports industry (16). Further, different types of entrepreneurs in sport can include the athletes, agents, towns, and the owners, as long as they are doing something in sport that is different from what has been done before. Also, sports entrepreneurs are people or organizations in sport that use innovation to solve business related issues in sport, and when solved, have the ability to change the business environment for the better (11).

One can see that entrepreneurs have many characteristics both psychologically and physically. Further, one learned that when entering the sport landscape with a new venture, it is vital to recognize and exploit opportunity, and also, to utilize the appropriate framework. Red Bull was able to accurately recognize opportunity by using social entrepreneurship to engage key stakeholders and in creating new extreme sports that correlated with the brand image. Women's pro volleyball leagues within the United States failed to sustain successful operations due to failing to recognize the landscape of creating a new sport franchise, and the need to legitimize it and gain sponsors for the long term. These leagues didn't realize the need for long-term planning, and only perceived through the entrepreneurial lens of starting quickly and legitimizing quickly, which they were not able to do.

\section{RECOMMENDATION}

This paper covered briefly the nature of entrepreneurship and of entrepreneurs, and also, the nature of entrepreneurship and sport. It examined two case studies, which presented the ways in which one can utilize different entrepreneurial strategies to succeed, and also, how to fail. Recommendations for future research could examine the demographics for those entrepreneurs who have started a sport venture and have maintained successful operations, and for those who have not. This type of research would add to the current demographic information on entrepreneurship, but could potentially uncover if demographics have an effect on the ability of sport entrepreneurs to manage a sport venture.

Further research could also examine educational level and educational focus of entrepreneurs who have successfully or unsuccessfully sustained a sport venture to see if educational level or educational focus correlates with ones ability to successfully run a sport venture, and also, to see what type of venture they start in relation to founder's identity. There is a great deal of research on entrepreneurship in academia, but very little research on sports entrepreneurship.

\section{CONCLuSion}

Entrepreneurs are a unique group of people who separate themselves from the rest by being opportunity-driven, goal-oriented, innovative, risk-taking, and leadership oriented, and in sports entrepreneurship one can imagine with personality characteristics like this, that one would also be able to devise an important strategy in starting and sustaining a sport business, but as was discussed, that's not always the case. It is important to emphasize that different ventures in sport need different considerations before implementing a strategy. As was shown, Red Bull correctly launched its product effectively by understanding the landscape for which it was entering, and in many cases, it created its own landscape that smoothly launched them into the sport industry.

Red Bull successfully legitimized its brand. However, women's volleyball leagues assumed they would automatically be legitimized and could grow quickly and sustain themselves, but they failed to realize that with a sport league in general, whether NFL, MLB, or NHL, it takes years or decades to legitimize, not the typical 1.5 years of an entrepreneurial venture. The key takeaways from this paper 
are to first recognize within oneself his or her entrepreneurial spirit, and realize the nature of the entrepreneur and entrepreneurship so that one can understand how that relates to the venture he or she wants to begin. Next, it is important to recognize that to launch a venture in sport, it takes the ability to strategize effectively, and also, the ability to recognize opportunity as it emerges. One needs to recognize the competitive landscape and the need for legitimizing oneself so that the sport venture can gain support for the long term. Lastly, it is to realize that even when one thinks that an entrepreneurial strategy will be effective, it may not be, and so it is important to be able to plan accordingly to deal with failure, and most importantly, to learn from failure, or those mistakes may repeat themselves.

\section{ACKNOWLEDGMENTS}

Dedicated to my mentor, friend, and former professor, Dr. Timothy Rice.

\section{REFERENCES}

[1] Birch, D. L. (1987). Job creation in America: How our smallest companies put the most people to work. New York, NY: Free Press.

[2] Carayannis, E. G., \& Stewart, M. R. (2013). Obsessed maniacs and clairvoyant oracles: empirically validated patterns of entrepreneurial behavior. Journal of Innovation and Entrepreneurship, 2(2). doi:10.1186/2192-5372-2-2

[3] Docekalova, I., Micelotta, E., \& Washington, M. (2014). It's about time! The role of temporal orientation and framing in entrepreneurial failure. Academy Of Management Annual Meeting Proceedings, 417-422. doi:10.5465/AMBPP.2014.31

[4] Entrepreneur. (n.d.). In Merriam-Webster. Retrieved from http://www.merriam-webster.com/ dictionary/entrepreneur

[5] Fauchart, E., \& Gruber, M. (2011). Darwinians, communitarians, and missionaries: The role of founder identity in entrepreneurship. Academy Of Management Journal, 54(5), 935-957. doi:10.5465/amj.2009.0211

[6] Gallagher, D., Gilmore, A., \& Stolz, A. (2012). The strategic marketing of small sports clubs: From fundraising to social entrepreneurship. Journal Of Strategic Marketing, 20(3), 231-247. doi:10.1080/0965254X.2012.657225

[7] Gschwandtner, G. (2004). The powerful sales strategy behind Red Bull. Selling Power.

[8] Retrieved from http://www.sellingpower.com/article/display.asp?aid=SP2229597

[9] Geri, S. (2013). Research on entrepreneurial characteristics of students in school of physical education and sports. Turkish Journal Of Education, 2(3), 50-60.

[10] Gorse, S., Chadwick, S., \& Burton, N. (2010). Entrepreneurship through sports marketing: A case analysis of Red Bull in sport. Journal Of Sponsorship, 3(4), 348-357.

[11] Hisrich, R. (1990). Entrepreneurship/intrapreneurship. American Psychologist, 45, 209-222.

[12] Hisrich, R., Peters, M., \& Shepherd, D. (2015). Sports entrepreneurship (9th ed.). New York, NY: McGraw Hill.

[13] Irwin, R.L., Zwick, D., and Sutton, W.A. (1999). Assessing organizational attributes contributing to marketing excellence in American professional sport franchises. European Journal of Sport Marketing, 33(3/4), 314-327.

[14] Lumpkin, G. T., \& Dess, G. G. (2001). Linking two dimensions of entrepreneurial orientation to firm performance: The moderating role of environment and industry life cycle. Journal of Business Venturing, 16, 429-451.

[15] McDermott, J. (2012). Who's an entrepreneur now? Inc. Retrieved from http://www.inc.com/ john-mcdermott/entrepreneur-demographics-whos-an-entrepreneur-now.html

[16] Ratten, V. (2010). Sport-based entrepreneurship: Towards a new theory of entrepreneurship and sport management. International Entrepreneurship and Management Journal, 7, 57-69.

[17] Ratten, V. (2011). Practical implications and future research directions for international sports management. Thunderbird International Business Review, 53(6), 763-770. doi:10.1002/tie.20451

[18] Schumpeter, J. A. (1965). Economic theory and entrepreneurial history. In H. G. Aitken (Ed.), Explorations in enterprise (pp. 45-64). Cambridge, MA: Harvard University Press. 
[19] Schumpeter, J. A. (1974). The theory of economic development. Oxford, England: Oxford University Press.

[20] Senne, J. A. (2016). Examination of gender equity and female participation in sport. The Sport Journal. Retrieved from http://thesportjournal.org/wp-content/uploads/kalins-pdf/singles/ examination-of-gender-equity-and-female-participation-in-sport.pdf

[21] Shinnar, R., Pruett, M. \& Toney, B. (2009). Entrepreneurship education: Attitudes across campus. Journal of Education for Business, 84(3), 151-159.

[22] Smagina, A. (2016). Entrepreneurship and entreprenerial opportunities. Conceptual framework. Proceedings Of The Multidisciplinary Academic Conference, 22-32.

[23] Timmons, J. A. (1997). New venture creation: Entrepreneurship for the 21st century (5th ed.). Boston, MA: Irwin McGraw-Hill.

[24] Wadhwa, V., Aggarwal, R., Holly, K., \& Salkever, A. (2009). The anatomy of an entrepreneur. Ewing Marion Kauffman Foundation. Retrieved from http://www.kauffman.org/what-wedo/research/2010/05/the-anatomy-of-an-entrepreneur

[25] Wilson, F., Marlino, D. \& Kickul, D. (2004). Our entrepreneurial future: Examining the diverse attitudes and motivations of teens across gender and ethnic identity. Journal of Developmental Entrepreneurship, 9(3), 177-197.

\section{AUTHOR'S BIOGRAPHY}

Joshua A. Senne is a doctoral student at the United States Sports Academy located in Daphne, Alabama. His doctoral emphasis is sports fitness and health, with a specialization in sport marketing. $\mathrm{He}$ currently holds a master of science in recreation and sport management from Indiana State University, a business credential from the Harvard Business School, and is a Stanford Certified Project Manager. 